\title{
Evaluation of alternative formulae for calculation of surface temperature in snowmelt models using frequency analysis of temperature observations
}

\author{
C. H. Luce ${ }^{1}$ and D. G. Tarboton ${ }^{2}$ \\ ${ }^{1}$ USDA Forest Service, Rocky Mountain Research Station, Boise, Idaho, USA \\ ${ }^{2}$ Civil and Environmental Engineering, Utah State University, Logan, Utah, USA \\ Received: 7 May 2009 - Published in Hydrol. Earth Syst. Sci. Discuss.: 19 May 2009 \\ Revised: 2 March 2010 - Accepted: 4 March 2010 - Published: 18 March 2010
}

\begin{abstract}
The snow surface temperature is an important quantity in the snow energy balance, since it modulates the exchange of energy between the surface and the atmosphere as well as the conduction of energy into the snowpack. It is therefore important to correctly model snow surface temperatures in energy balance snowmelt models. This paper focuses on the relationship between snow surface temperature and conductive energy fluxes that drive the energy balance of a snowpack. Time series of snow temperature at the surface and through the snowpack were measured to examine energy conduction in a snowpack. Based on these measurements we calculated the snowpack energy content and conductive energy flux at the snow surface. We then used these estimates of conductive energy flux to evaluate formulae for the calculation of the conductive flux at the snow surface based on surface temperature time series. We use a method based on Fourier frequency analysis to estimate snow thermal properties. Among the formulae evaluated, we found that a modified force-restore formula, based on the superimposition of the force-restore equation capturing diurnal fluctuations on a gradually changing temperature gradient, had the best agreement with observations of heat conduction. This formula is suggested for the parameterization of snow surface temperature in a full snowpack energy balance model.
\end{abstract}

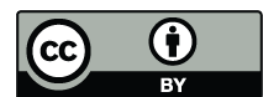

Correspondence to: C. H. Luce (cluce@fs.fed.us)

\section{Introduction}

Energy balance snowmelt models include calculations for the conduction of energy into the snow forced by surface energy exchanges. Many fluxes at the snow surface are functions of the snow surface temperature, which itself results from the balance of fluxes to and from the surface. This paper examines models for the calculation of conductive energy flux at the snow surface based on snow surface temperature using measured time series of snow temperature at the snow surface and through the snowpack. These measurements were made as part of an effort to validate the energy components of an energy balance snowmelt model and led to a more refined understanding of how to parameterize snow surface temperature in these models.

Conduction of heat from the snow surface into the snowpack depends on the temperature profile within the snow that results from the history of previous energy exchanges and surface temperatures interacting with snowpack thermal properties. If the heat flux into the snowpack were steady state, and snowpack thermal properties homogeneous, the temperature profile would be linear, and the temperature gradient constant with depth. Because snow surface heating varies over the course of a day and over longer time periods, the temperature profile is nonlinear with depth, leading to complexity in the evolution of temperature and energy fluxes.

One approach used by snowmelt models to account for this nonlinearity is to discretize the snow into multiple layers, using, for example, finite difference schemes (Yen, 1967; Anderson, 1976; Blöschl and Kirnbauer, 1991; Jordan, 1991; Gray et al., 1995; Marks et al., 1999; Bartelt and Lehning, 2002). Multiple layer models track heat stores and varying

Published by Copernicus Publications on behalf of the European Geosciences Union. 
gradients with depth using linear approximations, with thinner layers near the surface to represent the steeper and more nonlinear temperature profile. In addition, these finite difference models may estimate changes in snow properties within layers based on snow metamorphism (Colbeck, 1982; Jordan, 1991; Arons and Colbeck, 1995; Bartelt and Lehning, 2002). The vertically distributed temperature and snow property information internal to the snowpack is useful in some applications, such as determining crystal development at depth for snowpack strength or understanding microwave satellite information. However, for many snowmelt modeling purposes, the heat fluxes at the surface and the base of the snowpack (or other suitable control volume) are sufficient for an energy balance, and they depend on the temperature gradient and the properties of the snow at the surface and base.

Another approach, striving for parsimony, is to use a single layer or a small number of layers in a snowmelt model. Because inaccuracies in the modeling of internal snowpack property details could lead to substantial errors in estimating the vertically distributed snowpack temperature (Arons and Colbeck, 1995), a minimum of model complexity is desirable. This is a special case of the general principle of parsimony in modeling. Vertical integration of the snowpack energy distribution also provides computational savings for distributed modeling applications and may be an important initial step in constructing spatially integrated models (Horne and Kavvas, 1997; Luce et al., 1999; Luce and Tarboton, 2004). Some have investigated the problem from the point of view of minimizing the number of layers needed while still retaining essentially a finite difference solution (Jin et al., 1999; Marks et al., 1999).

One of the primary reasons cited for the poor performance of single-layer models in comparative validations is poor representation of internal snowpack heat transfer processes (Blöschl and Kirnbauer, 1991; Koivasulo and Heikinheimo, 1999). These authors have also specifically cited the errors being most pronounced during cold periods before melt occurs, indicating that heat flow more than water flow may be to blame. Evaluations of the Utah Energy Balance model (Tarboton and Luce, 1996; Koivasulo and Heikinheimo, 1999) showed that the model underestimated snowpack temperature during a cold spell because the conduction parameterization overestimated the conduction within the snowpack. An important question is whether this is a problem with the specific equilibrium gradient parameterization that this model used or if it is an intrinsic drawback to the use of a single layer model.

Frequency domain discretization is a common alternative to spatial domain discretization for a number of disciplines (Press et al., 1992). In frequency domain modeling, calculations are done across variations in frequency instead of across variations in space. Thus slow processes might be modeled as a low-frequency component and faster processes as high-frequency components. The force-restore approach is an example application of the concept for snowpack and soil temperature modeling considering a single dominant frequency (diurnal) of thermal forcing (Deardorff, 1978; Hu and Islam, 1995). The force-restore method has been applied for snowpack modeling in several land-surface hydrology components for regional and global circulation models (e.g. Dickinson et al., 1993). If we consider the frequency domain approach in a general way, we have the opportunity to test the utility of considering more than one frequency.

The purpose of this paper is to explore alternative formulae derived from different frequency domain discretizations that may be used to parameterize the conduction of energy into a snowpack based on the surface temperature time series and evaluate those formulae using observations of snowpack energy content. In Sect. 2 we first review the theory associated with the frequency and amplitude of temperature time series and conduction within snow based on the heat equation. We summarize important inferences regarding the lagging of phase and dampening of the amplitude of periodic forcing inputs with depth and indicate how measurements of these can be used to infer thermal properties. We then review, from the theory, the basis for formulae used to calculate the surface temperature and estimate the surface energy flux in snowmelt models. We suggest a modification to accommodate lower frequency variations. In Sect. 3 we describe the measurements of temperature and ground heat flux that we have used to test this theory. In Sect. 4 we describe the analysis that quantified the dampening and lagging of phase of temperature with depth to estimate thermal properties. We also describe the analysis of temperature time series used to calculate the internal energy of the snow and energy flux at the snow surface. Section 5 presents results where we show the snow thermal properties derived from the frequency analysis. These properties are then used in the comparison of formulae for calculation of conduction into the snow to compare energy content and conductive flux at the surface and base of the snowpack from these formulae to measurements.

\section{Theory}

\subsection{Conduction with sinusoidal forcing}

We can describe heat flow in the snowpack approximately using the diffusion, or heat, equation and assuming homogeneity of properties (Yen, 1967),

$$
\frac{\partial T}{d t}=k \frac{\partial^{2} T}{\partial z^{2}}
$$

where $T$ is the temperature $\left({ }^{\circ} \mathrm{C}\right), t$ is time (s), $z$ is depth $(\mathrm{m})$ measured downwards from the surface, and $k$ is the thermal diffusivity $\left(\mathrm{m}^{2} \mathrm{~s}^{-1}\right)$. Thermal diffusivity is related to thermal conductivity and specific heat through

$k=\lambda / C \rho$

where $\lambda$ is the thermal conductivity $\left(\mathrm{J} \mathrm{m}^{-1}{ }^{\circ} \mathrm{C}^{-1} \mathrm{~s}^{-1}\right), C$ is the specific heat $\left(\mathrm{J} \mathrm{kg}^{-1}{ }^{\circ} \mathrm{C}^{-1}\right)$, and $\rho$ is the snow density 
$\left(\mathrm{kg} \mathrm{m}^{-3}\right)$. The diurnal cycle that dominates snow energy fluxes can be approximated using a sinusoidal temperature fluctuation at the surface, or upper boundary, given by

$T_{s}=\bar{T}+A \sin (\omega t)$

where $T_{S}$ is the surface temperature $\left({ }^{\circ} \mathrm{C}\right), A$ is the amplitude of the temperature fluctuation at the surface $\left({ }^{\circ} \mathrm{C}\right), \bar{T}$ is the time average temperature at the surface $\left({ }^{\circ} \mathrm{C}\right)$, and $\omega$ is the angular frequency $\left(0.2618\right.$ radians $\mathrm{h}^{-1}$ for a diurnal forcing). For semi-infinite domain $(0<z<\infty)$, the differential Eq. (1) with boundary condition (Eq. 3) has solution (Berg and McGregor, 1966)

$T(z, t)=\bar{T}+A e^{-\frac{z}{d}} \sin \left(\omega t-\frac{z}{d}\right)$

In this solution, $d$ is the damping depth $(\mathrm{m})$, the depth at which the amplitude is 1/e times the surface amplitude. $d$ is related to the thermal diffusivity and frequency by $d=(2 k / \omega)^{1 / 2}$.

The heat flux, $Q_{c}\left(\mathrm{~W} \mathrm{~m}^{-2}\right)$, is the thermal conductivity times the temperature gradient

$Q_{c}(z, t)=-\lambda \frac{\partial T}{\partial z}$

Differentiating Eq. (4) with respect to $z$ and substituting in Eq. (5) gives

$Q_{c}(z, t)=\frac{\lambda}{d} A e^{-\frac{z}{d}}\left[\sin \left(\omega t-\frac{z}{d}\right)+\cos \left(\omega t-\frac{z}{d}\right)\right]$

Here $Q_{c}$ is defined as positive in the positive $z$ direction, which is into the snow.

Evaluating Eq. (6) at $z=0$ to obtain the surface heat flux, $Q_{c s}\left(\mathrm{~W} \mathrm{~m}^{-2}\right)$, and using a trigonometric identity for the sum of sine and cosine yields the surface heat flux as a function of time,

$Q_{\mathrm{cs}}=\frac{\sqrt{2} A \lambda}{d} \sin \left(\omega t+\frac{\pi}{4}\right)$.

This shows that the temperature lags the heat flux by $\pi / 4$ radians, which is $1 / 8$ of a cycle or $3 \mathrm{~h}$ for diurnal forcing.

Differentiating Eq. (4) with respect to time gives

$\frac{\partial T(z, t)}{\partial t}=A \omega e^{-z / d} \cos \left(\omega t-\frac{z}{d}\right)$

Comparing Eqs. (4) and (8) to (6), the sine term in Eq. (6) can, using Eq. (4), be replaced by $(\lambda / d)(T(z, t)-\bar{T})$ while the cosine term in Eq. (6) can, using Eq. (8), be replaced by $(\lambda / d)(1 / \omega) \partial T(z, t) / \partial t$ to give

$Q_{c}(z, t)=\frac{\lambda}{d}\left(\frac{1}{\omega} \frac{\partial T(z, t)}{\partial t}+T(z, t)-\bar{T}\right)$.

This is the basis for the force-restore method to estimate the surface heat flux (see also Eq. 10) of Hu and Islam, 1995).
Applied at the surface and using a finite difference approximation for $\partial T_{s} / \partial t$ results in an estimate

$Q_{\mathrm{cs}}=\frac{\lambda}{d}\left(\frac{1}{\omega \Delta t}\left(T_{s}-T_{S_{\text {lag } 1}}\right)+\left(T_{s}-\bar{T}\right)\right)$

where $\Delta t$ is the time step and $T_{s_{\mathrm{lag} 1}}$ is the surface temperature lagged by one time step, i.e. at $t-\Delta t$. For this approximation to be valid, $\Delta t$ must be small compared to the daily time scale.

\subsection{Modeling snow surface temperature}

In an energy balance snowmelt model it is important to connect the energy fluxes above the snow surface to the conduction of energy into the snow. Conservation of energy at the snow surface implies that the net energy exchanges above the surface, $Q_{A}$, must balance the net fluxes below the surface. $Q_{A}$ comprises net solar and longwave radiation, sensible and latent heat fluxes and the flux due to precipitation. While these are sometimes taken as external forcing to the snowmelt model, they do interact through dependence on $T_{s}$. For example outgoing longwave radiation is related to $T_{S}$ through the Stefan-Boltzman equation, while sensible heat flux is related to $T_{S}$ through the difference between $T_{S}$ and air temperature. Thus, in general, we can write $Q_{A}\left(T_{S}\right)$. The processes carrying heat from the surface into the snowpack comprise solid conduction, vapor phase diffusion, and infiltration of meltwater generated at the surface. The focus in this paper is on the conduction/diffusion components, $Q_{\text {cs }}$, which are driven by temperature gradients. Since conduction depends on temperature at the surface as well as the temperature profile within the snow, we write $Q_{\mathrm{cs}}\left(T_{s}, T_{\text {ave }}\right)$ to explicitly show the dependence on $T_{S}$, and to approximate the temperature within the snow as the average temperature of the snowpack, $T_{\text {ave, }}$ which tracks the bulk energy state of the snowpack in a snowmelt model. Noting that there is no storage of energy in a surface with no thickness, one can estimate $T_{S}$ in an energy-balance model by setting $Q_{A}\left(T_{S}\right)=Q_{\mathrm{cs}}\left(T_{s}, T_{\mathrm{ave}}\right)$ and solving for $T_{s}$. Three different formulae for approximating $Q_{\mathrm{cs}}\left(T_{s}, T_{\mathrm{ave}}\right)$ in this equation are evaluated here.

The first and simplest formula for calculating $T_{S}$ and estimating the surface heat flux was a linear equilibrium gradient approach that we used earlier (Tarboton, 1994; Tarboton et al., 1995; Tarboton and Luce, 1996). This estimates the conduction of heat from the surface into the snowpack as a function of the difference between the average snowpack temperature (as estimated from the energy content) and the surface temperature.

$Q_{\mathrm{cs}}=\frac{\lambda}{d}\left(T_{s}-T_{\mathrm{ave}}\right)$

This can be obtained as a direct finite difference approximation of Eq. (5), assuming that d represents an effective depth to the average temperature. It can also be obtained from 
Eq. (10) by neglecting the time gradient term and replacing $\bar{T}$ by $T_{\text {ave }}$. In this approximation the damping depth for a diurnal fluctuation has been used to scale the depth, $d$, over which the gradient is approximated, and temperature at this depth is taken as the average temperature of the snowpack, $T_{\text {ave }}$. The inclusion of $T_{\text {ave }}$, is key because it connects the calculation of surface temperature to the energy state of the snowpack. Without this connection to the physical dependence of $Q_{\mathrm{cs}}$ on temperature within the snow, as represented by $T_{\text {ave }}$, snow surface temperatures would evolve independently of the temperature of the rest of the snowpack, which does not reflect our physical understanding. Earlier work (Tarboton and Luce, 1996; Koivasulo and Heikinheimo, 1999) has shown that, when used in a snowmelt model with literature estimates of thermal conductivity, this equilibrium gradient approach results in an underestimation of snowpack temperature during a cold spell.

While $\bar{T}$ in Eq. (10) is identified as the steady-state time average surface temperature in Eq. (3), it may also be interpreted from Eq. (4) as an invarying temperature at infinite depth, or as the average temperature of the medium over the semi-infinite domain (Hu and Islam, 1995). To use Eq. (10) to calculate $T_{s}$ and surface heat flux, we replace $\bar{T}$ by $T_{\text {ave }}$, the average temperature of the snow over the finite depth of the snowpack.

$$
Q_{\mathrm{cs}}=\frac{\lambda}{d}\left(\frac{1}{\omega \Delta t}\left(T_{s}-T_{s_{\mathrm{lag} 1}}\right)+\left(T_{s}-T_{\mathrm{ave}}\right)\right)
$$

When equated to $Q_{A}\left(T_{S}\right)$ this provides the second formula for calculating $T_{s}$ and estimating heat flux in an energy balance snowmelt model.

The interpretation above of $\bar{T}$ as the average temperature over depth is only the case if the diurnal fluctuation solution of Eq. (4) is not superimposed on any steady gradient or lower frequency fluctuations. To account for lower frequency fluctuations or a constant temperature gradient we can add to Eq. (10) the flux due to the vertical gradient in temperature averaged at a daily scale. This gradient is estimated using the difference in the daily average surface temperature, $\bar{T}_{s}$, and the daily average depth average snowpack temperature, $\bar{T}_{\text {ave }}$, evaluated over a distance $d_{\mathrm{lf}}$.

$$
Q_{\mathrm{cs}}=\frac{\lambda}{d}\left(\frac{1}{\omega \Delta t}\left(T_{s}-T_{s_{\mathrm{lag} 1}}\right)+\left(T_{s}-\bar{T}_{s}\right)\right)+\frac{\lambda}{d_{\mathrm{lf}}}\left(\bar{T}_{s}-\bar{T}_{\mathrm{ave}}\right)
$$

In this equation, we also substituted the daily average surface temperature, $\bar{T}_{s}$, for $\bar{T}$. This approximation combines the diurnal cycle flux (Eq. 10), calculated over the time scale of one day with a finite difference approximation similar to Eq. (11) at longer time scales. The subscript, "lf", on $d_{\text {lf }}$ indicates lower frequency. We estimated $d_{\mathrm{lf}}$ based on the depth of penetration of a lower frequency surface temperature fluctuation responsible for setting up this gradient, $d_{\mathrm{lf}}=\left(2 k / \omega_{\mathrm{lf}}\right)^{1 / 2}$. The appropriate low frequency, $\omega_{\mathrm{lf}}$, to use is not known; so in this paper, $\omega_{\mathrm{lf}}$ is fitted to observations.
Equations (11), (12) and (13) are formulae that can be used to parameterize conduction in a snowmelt model. Here we evaluate each against measurements.

\section{Measurements}

The measurements used in this analysis were previously reported in Tarboton (1994) as part of a test of the UEB snowmelt model (Tarboton et al., 1995; Tarboton and Luce, 1996). Measurements were taken at the Utah State University Drainage Research Farm, west of Logan, Utah, near the center of Cache Valley. Cache Valley is situated in the Wasatch Mountains, east of the Great Salt Lake in Utah and is similar to many valleys formed by faulting in the Basin and Range Province of the western United States. It is oriented north and south, about $110 \mathrm{~km}$ long and $15 \mathrm{~km}$ wide, between two high ranges on the east and west, each about $1500 \mathrm{~m}$ higher than the valley floor, making the valley prone to long winter inversions.

Snowpack and shallow soil temperatures were measured using eight copper-constantin thermocouples and an infrared thermometer. Two thermocouples were placed below the ground surface at depths of 2.5 and $7.5 \mathrm{~cm}$. Another thermocouple was placed at the ground surface, and the remaining five thermocouples were placed at 5, 12.5, 20, 27.5, and $35 \mathrm{~cm}$ above the ground surface on a ladder constructed of fishing line. Snowpack surface temperature was measured with two Everest Interscience model 4000 infrared thermometers with 15-degree field of view. Time series of these temperature measurements are shown in Fig. 1. Ground heat flux was measured with a REBS ground heat flux plate placed at $10 \mathrm{~cm}$ depth in the soil. Measurements were taken each half-hour.

\section{Analysis}

Equation (4) forms the basis for a Fourier analysis of temperature time series at multiple depths to estimate snowpack properties. Fourier analysis of a single temperature trace provides estimates of the phase and amplitude of that trace for a given frequency, diurnal in this case. Contrasting the phase and amplitude of different layers provides an estimate of the thermal properties between the measurements. Fourier analyses of temperature time series in snowpacks have been used in the past with best results for large diurnal temperature signals (Sturm et al., 1997). We know of no implementations of this technique using modern sensors and sub-hourly data.

We examined the temperature patterns over 8 days of the study period from 26 January to 2 February 1993, selected because of lack of melt or accumulation. A function, $f$, spanning the full 8-day (192-h) duration, $L$, sampled on 


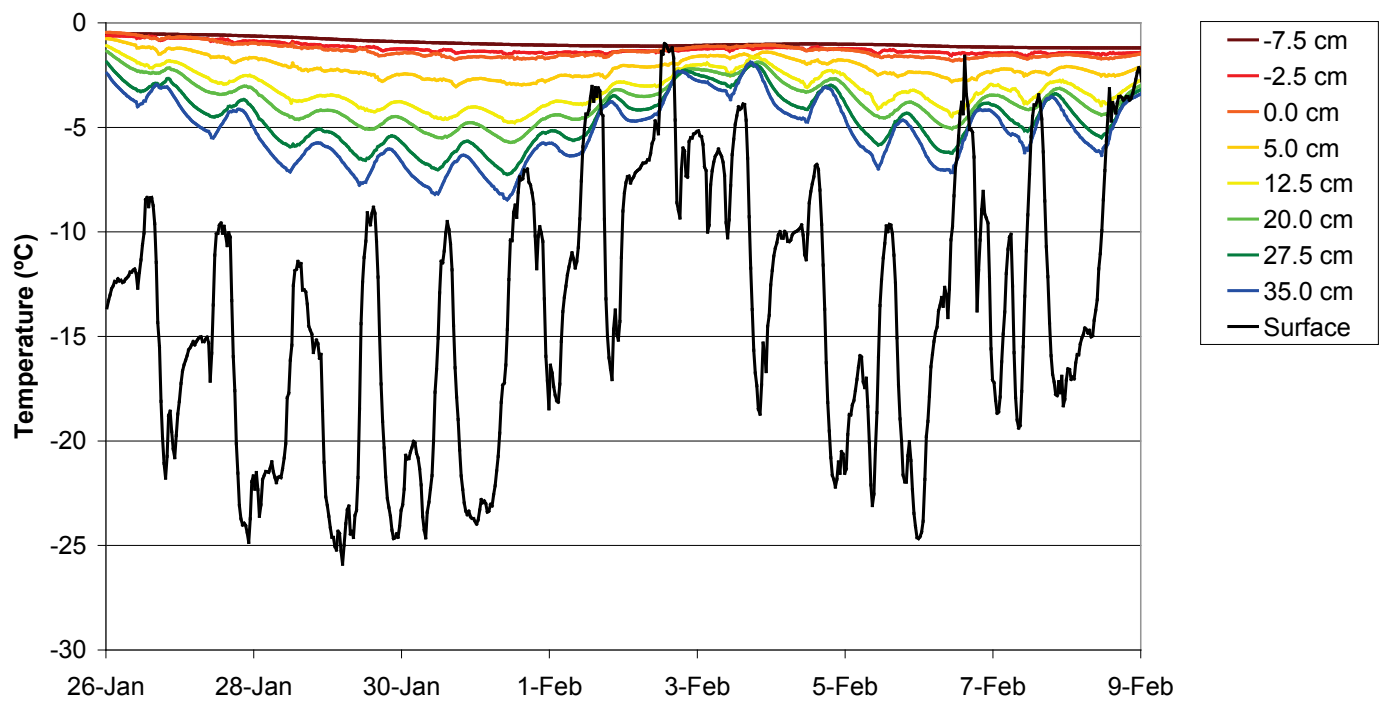

Fig. 1. Temperature time series from thermocouples and infrared thermometer (surface). The legend mimics the sequence of lines in the graphs, with warmer temperatures (and colors) corresponding to deeper thermocouples. Zero and positive values give depths above the ground surface within the snow. Negative distances refer to thermocouples beneath the ground. The snow was $39 \mathrm{~cm}$ deep during this period.

equal time steps, $\Delta t$, may be approximated by its Fourier series

$f(t)=\bar{f}+\sum_{k=1}^{n / 2} a_{k} \cos \left(k \omega_{0} t\right)+b_{k} \sin \left(k \omega_{0} t\right)$

where

$\omega_{0}=\frac{2 \pi}{L}$

and $n$ is the number of observations $(n=L / \Delta t)$.

The Fourier coefficients, $a_{k}$ and $b_{k}$, quantify the amplitude and phase associated with each frequency $\omega_{k}=k \omega_{0}$ that is present in the Fourier decomposition of the function. They may be estimated from discrete data by

$a_{k}=\frac{2 \sum_{j=0}^{n-1} f_{j} w_{j} \cos \left(\omega_{k} j \Delta t\right)}{\sum_{j=0}^{n-1} w_{j}}$

$b_{k}=\frac{2 \sum_{j=0}^{n-1} f_{j} w_{j} \sin \left(\omega_{k} j \Delta t\right)}{\sum_{j=0}^{n-1} w_{j}}$

where $w_{j}$ are the weights applied to each observation using a window function. We used a Parzen window, which gives the weights as,

$w_{j}=1-\left|\frac{j-\frac{1}{2}(n-1)}{\frac{1}{2}(n+1)}\right|$
Press et al. (1992). In our analysis, we are interested in the diurnal frequency, with period, $\tau=24 \mathrm{~h}$. For an analysis duration of $192 \mathrm{~h}$, this corresponds to 8 cycles, or $k=8$. We estimated $a_{8}$ and $b_{8}$ from Eqs. (18) and (19). Noting the trigonometric identity

$a_{8} \cos \left(8 \omega_{0} t\right)+b_{8} \sin \left(8 \omega_{0} t\right)=A \sin \left(8 \omega_{0} t+\phi\right)$

we can calculate

$A=\sqrt{a_{8}^{2}+b_{8}^{2}}$

and

$\phi=\frac{a_{8}}{\left|a_{8}\right|} \cos ^{-1}\left(\frac{b_{8}}{A}\right)$

For negative values of $\phi$, we added $2 \pi$. The differences in the value of $\phi$ between the surface and each layer were used to calculate of the value of $z / d$ for each layer from the sine term of Eq. (4). Similarly, the value of $z / d$ was estimated from the natural log of the ratios of the amplitude at the layer's temperature to the amplitude of the surface temperature, considering the exponential decay term in Eq. (4). Knowing the vertical position of each measurement in the snowpack, we calculated $d$, which provides a direct estimate of the diffusivity, $k$. Snowpack density (observed average of $260 \mathrm{~kg} \mathrm{~m}^{-3}$ in our study) and the specific heat of ice $\left(2.09 \mathrm{~kJ} \mathrm{~kg}^{-1}\right)$ were then used to estimate a value of conductivity, $\lambda$, from Eq. (2). The parameters estimated in this manner were used in the comparisons between the equations used to estimate surface heat fluxes.

The energy content of a control volume comprising the snow and soil above the heat flux plate buried at $10 \mathrm{~cm}$ was estimated from the average snowpack temperature, the average soil temperature, and the snowpack surface temperature. 


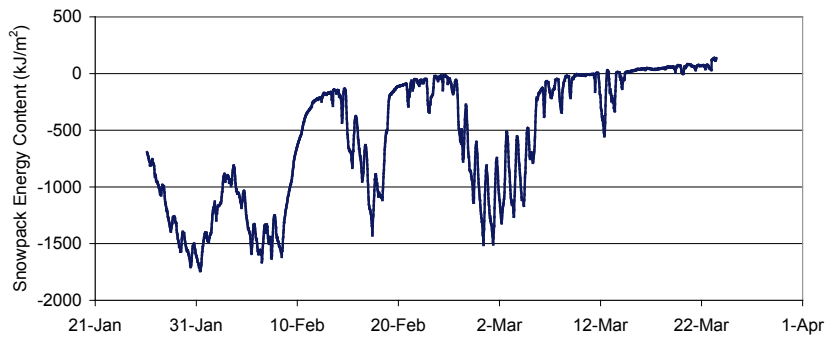

Fig. 2. Snowpack energy content over time.

For layers of the snowpack and soil between thermocouples, we used the average temperature between the thermocouples. Taking $0^{\circ} \mathrm{C}$ ice as having 0 energy content, the energy content without any liquid water present in the snowpack is,

$U=\left\langle T_{\text {snow }}\right\rangle W_{\text {snow }} \rho_{w} C_{\text {ice }}+\left\langle T_{\text {soil }}\right\rangle \rho_{\text {soil }} C_{\text {soil }} D_{e}$

where $\left\langle T_{\text {snow }}\right\rangle$ is the depth averaged snow temperature and $\left\langle T_{\text {soil }}\right\rangle$ is the depth averaged soil temperature over the depth of the soil above the heat flux plate, $D_{e}(0.1 \mathrm{~m}), W_{\text {snow }}$ is the water equivalent of the snowpack $(\mathrm{m}), \rho_{w}$ is the density of water $\left(1000 \mathrm{~kg} \mathrm{~m}^{-3}\right), \rho_{\text {soil }}$ is the density of soil $\left(1700 \mathrm{~kg} \mathrm{~m}^{-3}\right), C_{\text {ice }}$ is the specific heat of ice $\left(2.09 \mathrm{~kJ} \mathrm{~kg}^{-1}\right)$ and $C_{\text {soil }}$ is the specific heat of soil $\left(2.09 \mathrm{~kJ} \mathrm{~kg}^{-1}\right)$. This measure of the energy content can only record energy content when there is no water in the snowpack; thus it can only reliably calculate $U<0$. For periods when $U$ is greater than 0 due to the presence of liquid water in the snowpack, this Eq. (22) results in an underestimate that serves as a lower bound on $U$. Figure 2 shows the snowpack energy content as measured by snowpack temperature over the study period; positive estimates result from ground temperatures greater than 0 with a shallow snowpack.

Figure 3 shows the magnitude of heat fluxes at the surface of the snowpack inferred from the time series of energy content and measured ground heat flux necessary to explain the observed changes in snowpack energy content. During the first two weeks of the period, all parts of the snowpack were below freezing, so the energy content as measured by the temperature is an accurate description of the energy of the snowpack. During this period, there is an opportunity to examine how to model changes in snowpack energy that relate to the average snowpack temperature.

\section{Results and discussion}

\subsection{Thermal properties}

Table 1 presents thermal diffusivity values estimated from the Fourier analysis and an estimate of the conductivity based on the snowpack average density. The snow depth during this period was $39 \mathrm{~cm}$ and the analysis used the thermocouples at $0,5,12.5,20$, and $27.5 \mathrm{~cm}$ above the ground. The thermocouple $35 \mathrm{~cm}$ above the ground was not used in the analysis

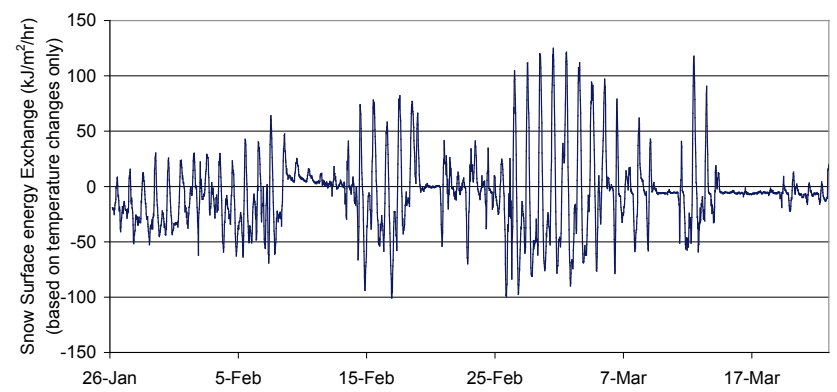

Fig. 3. Snowpack surface energy fluxes over duration of study period reported at half-hourly intervals.

because the precision of its position relative to the snow surface was relatively worse and the results from it were unrealistic, presumably due to this positioning inaccuracy. In Table $1 \mathrm{a}, z$ is the depth of the thermocouple from the snow surface; $\phi$ is the phase of the temperature cycle from Eq. (21); and $z / d$ is calculated based on the difference in phase between the surface and the thermocouple using Eq. (4) Knowing $z$, we have an estimate of $d$, which is related to diffusivity, $k$, by $d=(2 k / \omega)^{1 / 2}$ and finally $\lambda$ by Eq. (2). In Table $1 \mathrm{~b}$ the amplitude of the diurnal variation at each measurement point is calculated by Eq. (20), and the ratio of the amplitude at each layer to the amplitude at the surface gives $\exp (-z / d)$ from Eq. (4). The $\log$ of this gives $z / d$, and the remainder of the calculations in Table $1 \mathrm{~b}$ are the same as for Table 1a. The agreement (generally within 10\%) between the results considering just relative timing and those considering just relative amplitude supports use of the Fourier analysis procedure with diurnal forcing.

As might be expected, the properties for the upper snow layers differ from those of the lower layers, suggesting an increase in effective conductivity that may be related to increases in density with depth. Although the heat Eq. (1) assumes homogeneity of snowpack thermal properties, it has been shown for heat conduction problems that a nonhomogeneous diffusivity can be reasonably approximated by effective parameters in the heat equation within constraints of limited heterogeneity (Hanks et al., 1971).

For comparison among the three equations, there is a need for an estimate of the effective density and conductivity. Because most of the variation in energy takes place in the upper portion of the snowpack, we took the average of the conductivity values of the upper layer from the phase and amplitude analyses, $\lambda=0.058 \mathrm{~W} \mathrm{~m}^{-1}{ }^{\circ} \mathrm{C}^{-1}$ as the best estimate. For reference, Sturm et al. (1997) estimate thermal conductivity to average $0.093 \mathrm{~W} \mathrm{~m}^{-1}{ }^{\circ} \mathrm{C}^{-1}$ at a density of $260 \mathrm{~kg} \mathrm{~m}^{-3}$ with a range of $0.04 \mathrm{~W} \mathrm{~m}^{-1}{ }^{\circ} \mathrm{C}^{-1}$ to $0.20 \mathrm{~W} \mathrm{~m}^{-1}{ }^{\circ} \mathrm{C}^{-1}$ in the observations he reports. 
Table 1. Effective thermal parameters averaged from surface to depth $\mathrm{z}$ using (a) timing and (b) amplitude information as independent estimates. Conductivity was calculated using estimated density of $260 \mathrm{~kg} \mathrm{~m}^{-3}$.

\begin{tabular}{rccccc}
\hline \multicolumn{3}{l}{ (a) Phase shift analysis } & \multicolumn{3}{l}{} \\
\hline $\begin{array}{c}\phi \\
\mathrm{cm}\end{array}$ & $\begin{array}{c}\phi \\
\text { radians }\end{array}$ & & $\begin{array}{c}d \\
\mathrm{~cm}\end{array}$ & $\begin{array}{c}k \\
\mathrm{~m}^{2} \mathrm{~s}-1\end{array}$ & $\begin{array}{c}\lambda \\
\mathrm{W} \mathrm{m}-1{ }^{\circ} \mathrm{C}\end{array}$ \\
\hline 0 & 4.23 & 0.00 & & & \\
11.5 & 2.19 & 2.04 & 5.64 & $1.16 \mathrm{E}-07$ & 0.063 \\
19 & 1.78 & 2.44 & 7.78 & $2.20 \mathrm{E}-07$ & 0.120 \\
26.5 & 1.47 & 2.75 & 9.63 & $3.37 \mathrm{E}-07$ & 0.183 \\
34 & 0.62 & 3.61 & 9.43 & $3.23 \mathrm{E}-07$ & 0.176 \\
39 & 0.02 & 4.21 & 9.27 & $3.13 \mathrm{E}-07$ & 0.170
\end{tabular}

\begin{tabular}{rcccccc}
\hline \multicolumn{7}{l}{ (b) Amplitude analysis } \\
\hline $\begin{array}{r}z \\
\mathrm{~cm}\end{array}$ & $\begin{array}{c}\text { Amplitude } \\
{ }^{\circ} \mathrm{C}\end{array}$ & $\exp (-z / d)$ & $z / d$ & $\begin{array}{c}d \\
\mathrm{~cm}\end{array}$ & $\begin{array}{c}k \\
\mathrm{~m}^{2} \mathrm{~s}^{-1}\end{array}$ & $\begin{array}{c}\lambda \\
\mathrm{W} \mathrm{m}-1^{\circ} \mathrm{C}\end{array}$ \\
\hline 0 & 5.52 & 1.00 & 0.00 & & & \\
11.5 & 0.59 & 0.11 & 2.23 & 5.16 & $9.67 \mathrm{E}-08$ & 0.053 \\
19 & 0.35 & 0.06 & 2.75 & 6.92 & $1.74 \mathrm{E}-07$ & 0.095 \\
26.5 & 0.28 & 0.05 & 2.97 & 8.91 & $2.89 \mathrm{E}-07$ & 0.157 \\
34 & 0.11 & 0.02 & 3.96 & 8.58 & $2.68 \mathrm{E}-07$ & 0.145 \\
39 & 0.04 & 0.01 & 4.86 & 8.02 & $2.34 \mathrm{E}-07$ & 0.127 \\
\hline
\end{tabular}

\subsection{Model comparison}

Equations (11-13) estimate the conductive heat flux at the surface of the snowpack as a function of the history of surface temperature and the current energy content of the snowpack. With direct measurements of the surface temperature and the ground heat flux, we were able to model the time evolution of snowpack energy content and surface heat conduction fluxes without examining the details of the surface energy balance (e.g. net radiation).

For Eq. (11), the equilibrium gradient equation, and Eq. (12), the force-restore equation, the independently estimated parameter value of $\lambda=0.058 \mathrm{~W} \mathrm{~m}^{-1}{ }^{\circ} \mathrm{C}^{-1}$ yielded very low energy contents relative to observations. However by changing the conductivity to $0.01 \mathrm{~W} \mathrm{~m}^{-1}{ }^{\circ} \mathrm{C}^{-1}$ for the equilibrium gradient (Eq. 11) and $0.007 \mathrm{~W} \mathrm{~m}^{-1}{ }^{\circ} \mathrm{C}^{-1}$ for the force-restore (Eq. 12) approximate fits were possible (Fig. 4). These are unrealistically low thermal conductivity values, and result in severe damping of the daily variations in energy content. Equation (13), the modified force-restore equation, worked well with the conductivity independently estimated from the frequency analysis and calibrating $\omega_{\mathrm{lf}}$, with the resultant value corresponding to a period of 8.7 days, or using $d_{\mathrm{lf}}=\left(2 \mathrm{k} / \omega_{\mathrm{lf}}\right)^{1 / 2}$, an effective depth of $16 \mathrm{~cm}$. The suggestion is that physically realistic estimates of thermal conductivity from formulae (e.g. Sturm et al., 1997) could be used with such a model, leaving only a question about appropriate values for $\omega_{\mathrm{lf}}$.

Comparing half-hourly surface heat flux estimates from the modified force-restore Eq. (13) to observations (Fig. 5) shows strong agreement to fluctuations at this time scale.
This comparison uses conductivity and half-hourly changes in internal energy (Fig. 3) derived from temperature measurements that include the surface temperature, so is not a completely independent test of the model. Nevertheless, the modified force restore result in Fig. 5 is derived primarily from the observed surface temperature and suggests the accuracy to which the conduction of energy into a snowpack can be parameterized in an energy balance snowmelt model based on surface temperature forcing alone. The largest disagreements are generally less than $10 \mathrm{~W} \mathrm{~m}^{-2}$ in the early evening hours when the observed fluctuations in surface flux are not sinusoidal, but show an abrupt reduction in cooling. Records from a nearby airport suggest that this is likely related to the formation of fog at that time and the consequent reduction in net longwave losses (Luce, 2000).

Comparing surface heat flux estimates from all three equations (Fig. 6) is more easily done with a 3 -h average and shows that the equilibrium gradient approach (Eq. 11) produces a damped and lagged signal relative to the observations and modified force-restore (Eq. 13), and the force-restore model (Eq. 12) is in phase but damped.

Figure 7 compares 3-h average surface heat flux from the modified force restore equation where now both snow conductivity, $\lambda$, and lower frequency parameter, $\omega_{\mathrm{lf}}$, were calibrated. Adjustments to $\omega_{\mathrm{lf}}$ move the modeled line vertically while adjustments to conductivity change the amplitude of the diurnal fluctuations. At the half-hourly time scale, the Nash-Sutcliffe (Nash and Sutcliffe, 1970) coefficient of agreement goes from 0.58 without calibration to 0.73 when conductivity is calibrated. The calibrated parameters are, 


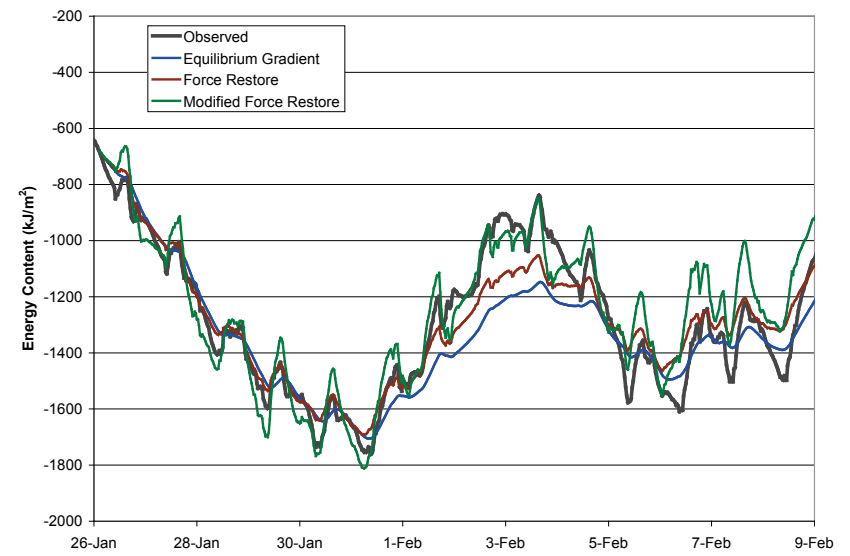

Fig. 4. Measured and modeled energy content during first 2 weeks. Equilibrium gradient parameter used in Eq. 11 was $\lambda=0.01 \mathrm{~W} \mathrm{~m}^{-1}{ }^{\circ} \mathrm{C}^{-1}$. Force restore parameter used in Eq. 12 was $\lambda=0.007 \mathrm{~W} \mathrm{~m}^{-1}{ }^{\circ} \mathrm{C}^{-1}$. Modified force restore parameters used in Eq. 13 were $\lambda_{\mathrm{lf}}=0.058 \mathrm{~W} \mathrm{~m}^{-1}{ }^{\circ} \mathrm{C}^{-1}, \omega_{\mathrm{lf}}$ corresponding to 8.7 days, $d_{\mathrm{lf}}=\left(2 \mathrm{k} / \omega_{\mathrm{lf}}\right)=16 \mathrm{~cm}$.

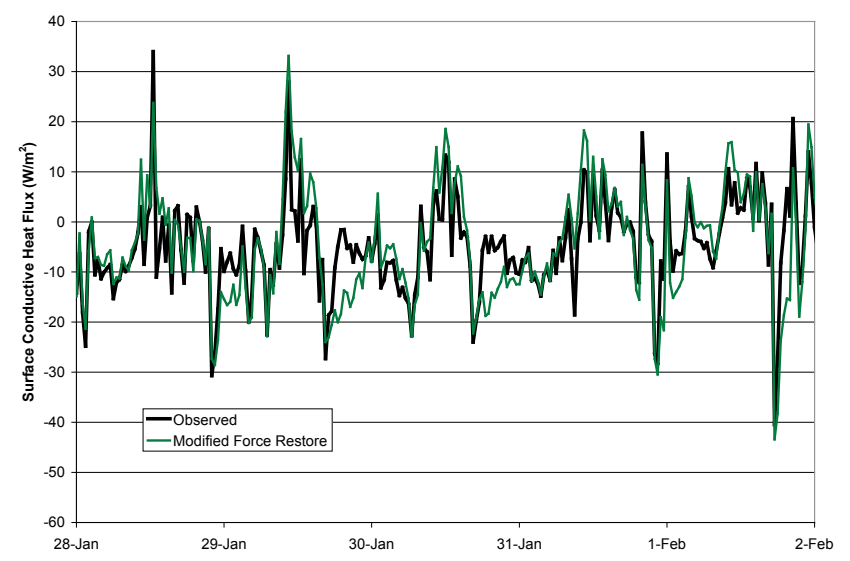

Fig. 5. Half-hourly surface conductive heat fluxes, observed and estimated from modified force-restore equation. Parameters used in Eq. 13 were $\lambda=0.058 \mathrm{~W} \mathrm{~m}^{-1}{ }^{\circ} \mathrm{C}^{-1}, \omega_{\mathrm{lf}}$ corresponding to 8.7 days, $d_{\mathrm{lf}}=\left(2 \mathrm{k} / \omega_{\mathrm{lf}}\right)=16 \mathrm{~cm}$.

conductivity, $\lambda=0.025 \mathrm{~W} \mathrm{~m}^{-1}{ }^{\circ} \mathrm{C}^{-1}$ and $\omega_{\mathrm{lf}}$ corresponding to a 3.7 day low frequency period, with effective depth $d_{\mathrm{lf}}=\left(2 \mathrm{k} / \omega_{\mathrm{lf}}\right)^{1 / 2}$, of $7 \mathrm{~cm}$. These adjustments push conductivity just out of the range reported by Sturm et al. (1997). While calibration of both conductivity and low frequency period does improve the comparisons to measured energy fluxes, it is reassuring that using the directly measured conductivity and only calibrating $\omega_{\mathrm{lf}}$ does result in quite good comparisons.

\section{Conclusions}

Heat flow through the snowpack is considered a difficult and complex process to model. So much so, that it has been generally assumed that single-layer snowpack models must,

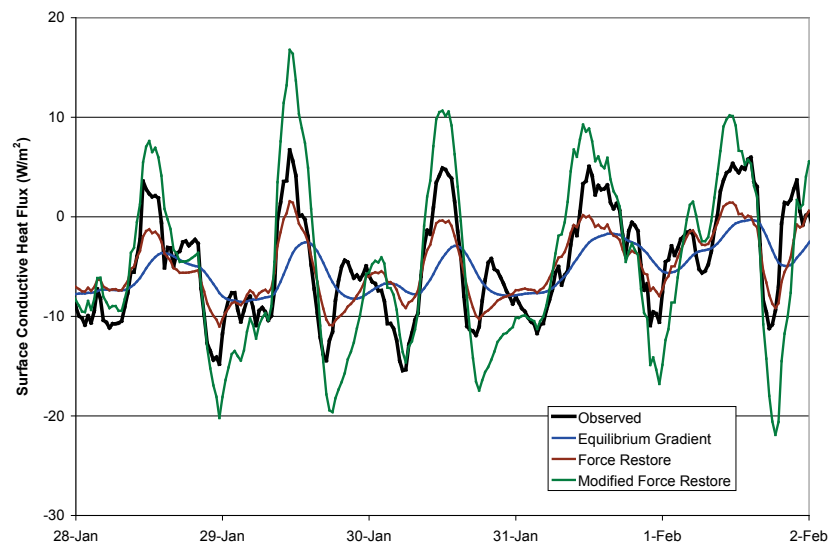

Fig. 6. Three-hour average surface conductive heat flux observations compared to three models over 5 day period. Equilibrium gradient parameter used in Eq. 11 was $\lambda=0.01 \mathrm{~W} \mathrm{~m}^{-1}{ }^{\circ} \mathrm{C}^{-1}$. Force restore parameter used in Eq. 12 was $\lambda=0.007 \mathrm{~W} \mathrm{~m}^{-1}{ }^{\circ} \mathrm{C}^{-1}$. Modified force restore parameters used in Eq. 13 were $\lambda=0.058 \mathrm{~W} \mathrm{~m}^{-1}{ }^{\circ} \mathrm{C}^{-1}, \omega_{\text {lf }}$ corresponding to 8.7 days, $d_{\mathrm{lf}}=\left(2 k / \omega_{\mathrm{lf}}\right)=16 \mathrm{~cm}$.

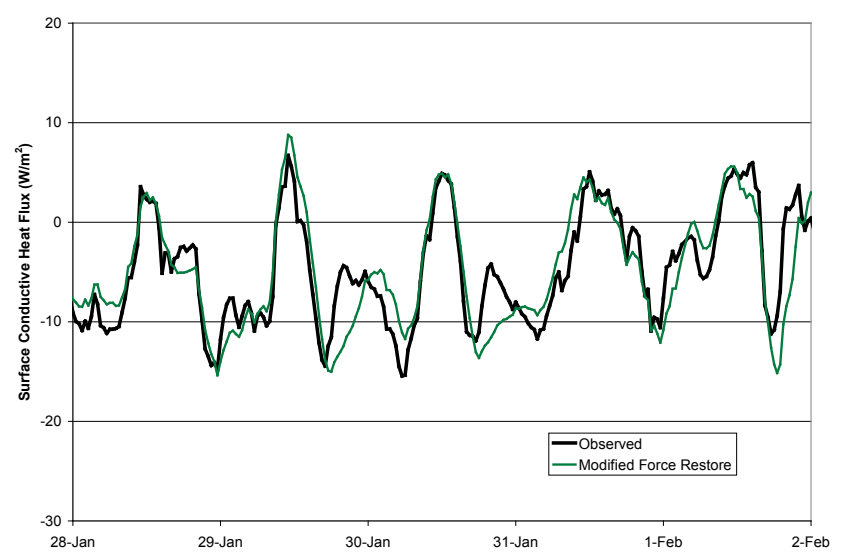

Fig. 7. Three-hour average surface conductive heat flux observations compared to modified force restore formula calibrated to more closely approximate the diurnal range in surface heat fluxes. Parameters used in Eq. 13 were $\lambda=0.025 \mathrm{~W} \mathrm{~m}^{-1}{ }^{\circ} \mathrm{C}^{-1}, \omega_{\text {lf }}$ corresponding to 3.7 days, $d_{\mathrm{lf}}=\left(2 k / \omega_{\mathrm{lf}}\right)=7 \mathrm{~cm}$.

of necessity, err in estimates of heat conduction, with their worst performance during cold periods. Making use of the fact that the heating and cooling of the snowpack is primarily diurnally forced, we substantially improved our descriptions of heat flow in the snowpack. By recognizing further that there are lower frequency forcings we can improve descriptions for extended cold periods. Equation (13), based on a force-restore model with a superimposed gradient, was shown to reproduce measured half-hourly and three hour average surface energy fluxes, as well as aggregate energy content quite well using an independently measured thermal conductivity and a calibrated low frequency parameter. This suggests that this formula is a good candidate for the parameterization of surface energy flux and calculation of 
surface temperature in an energy balance snowmelt model. This formula calculates energy flux without detailed information on the distribution of temperature over depth, so presents a potential to approximate more complex multilayer models in applications where computational simplifications may be useful, as in lumped modeling of spatially heterogeneous snowpacks. Our analysis shows a reasonable approximation in this case, and there would be benefit to testing against more complex models and observations in other environments.

Following the logic of this approach to the extreme, we could recognize that the forcing at the surface could be decomposed into a Fourier series with multiple frequencies. Estimation of the parameters for that series would use the time series of all previous surface temperatures - essentially the same information used in finite difference models. In principle the two numerical schemes would converge on a very similar answer. Within this concept lies the seed for simplification. If we can recognize those few frequencies with the greatest power, we can continue to represent the snowpack as a single-layer, and only use such recent past temperature information as needed.

Acknowledgements. This work was supported by NASA Land Surface Hydrology Program, grant number NAG 5-7597. The views and conclusions expressed are those of the authors and should not be interpreted as necessarily representing official policies, either expressed or implied, of the US Government.

Edited by: W. Quinton

\section{References}

Anderson, E. A.: A Point Energy and Mass Balance Model of a Snow Cover, U.S. Department of Commerce, Silver Spring, Md.NOAA Technical Report NWS 19, 150 pp., 1976.

Arons, E. M. and Colbeck, S. C.: Geometry of heat and mass transfer in dry snow: a review of theory and experiment, Rev. Geophys., 33, 463-493, 1995.

Bartelt, P. and Lehning, M.: A physical SNOWPACK model for the Swiss avalanche warning Part I: numerical model, Cold Reg. Sci. Technol., 35, 123-145, 2002.

Berg, P. W. and McGregor, J. L.: Elementary Partial Differential Equations, Holden-Day, Oakland, 421 pp., 1966.

Blöschl, G. and Kirnbauer, R.: Point Snowmelt Models with Different Degrees of Complexity - Internal Processes, J. Hydrol., 129, 127-147, 1991.

Colbeck, S. C.: An overview of seasonal snow metamorphism, Rev. Geophys. Space Ge., 20, 45-61, 1982.

Deardorff, J. W.: Efficient prediction of ground surface temperature and moisture with inclusion of a layer of vegetation, J. Geophys. Res., 83, 1889-1903, 1978.

Dickinson, R. E., Henderson-Sellers, A., and Kennedy, P. J.: Biosphere-Atmosphere Transfer Scheme (BATS) Version 1e as Coupled to the NCAR Community Climate Model, National Center for Atmospheric Research, Boulder, Colo.NCAR/TN387+STR, 72 pp., 1993.
Gray, J. M. N. T., Morland, L. W., and Colbeck, S. C.: Effect of change in thermal properties on the propagation of a periodic thermal wave: application to a snow-buried rocky outcrop, J. Geophys. Res., 100, 15267-15279, 1995.

Hanks, R. J., Austin, D. D., and Ondrechen, W. T.: Soil Temperature Estimation by a Numerical Method, Soil Sci. Soc. Am. Proc., 35, 665-667, 1971.

Horne, F. E. and Kavvas, M. L.: Physics of the spatially averaged snowmelt process, J. Hydrol., 191, 179-207, 1997.

$\mathrm{Hu}, \mathrm{Z}$. and Islam, S.: Prediction of Ground Surface Temperature and Soil Moisture Content by the Force-Restore method, Water Resour. Res., 31, 2531-2539, 1995.

Jin, J., Gao, X., Yang, Z.-L., Bales, R. C., Sorooshian, S., Dickinson, R. E., Sun, S. F., and Wu, G. X.: Comparative Analyses of Physically Based Snowmelt Models for Climate Simulations, J. Climate, 12, 2643-2657, 1999.

Jordan, R.: A one-dimensional temperature model for a snow cover, Technical documentation for SNTHERM.89, US Army CRREL, Hanover, N.H. Special Technical Report 91-16, 49 pp., 1991.

Koivasulo, H. and Heikinheimo, M.: Surface energy exchange over a boreal snowpack: Comparison of two snow energy balance models, Hydrol. Process., 13, 2395-2408, 1999.

Luce, C. H., Tarboton, D. G., and Cooley, K. R.: Subgrid Parameterization Of Snow Distribution For An Energy And Mass Balance Snow Cover Model, Hydrol. Process., 13, 1921-1933, 1999.

Luce, C.: Scale influences on the representation of snowpack processes, Civil and Environmental Engineering, Utah State University, Logan, Utah, 202 pp., 2000.

Luce, C. and Tarboton, D. G.: The Application of Depletion Curves for Parameterization of Subgrid Variability of Snow, Hydrol. Process., 18, 1409-1422, 2004.

Marks, D., Domingo, J., Susong, D., Link, T., and Garen, D.: A spatially distributed energy-balance snowmelt model for application in mountain basins, Hydrol. Process., 13, 1935-1959, 1999.

Nash, J. E. and Sutcliffe, J. V.: River Flow Forecasting Through Conceptual Models, 1. A Discussion of Principles, J. Hydrol., 10, 282-290, 1970.

Press, W. H., Teukolsky, S. A., Vetterling, W. T., and Flannery, B. P.: Numerical Recipes in FORTRAN: The Art of Scientific Computing, Second Edn., Cambridge University Press, New York, 1992.

Sturm, M., Holmgren, J., König, M., and Morris, K.: The thermal conductivity of seasonal snow, J. Glaciol., 43, 26-41, 1997.

Tarboton, D. G.: Measurement and Modeling of Snow Energy Balance and Sublimation From Snow, International Snow Science Workshop Proceedings, Snowbird, Utah, 260-279, 1994.

Tarboton, D. G., Chowdhury, T. G., and Jackson, T. H.: A Spatially Distributed Energy Balance Snowmelt Model, Biogeochemistry of Seasonally Snow-Covered Catchments, Boulder, Colo., 141$155,1995$.

Tarboton, D. G. and Luce, C. H.: Utah Energy Balance Snow Accumulation and Melt Model (UEB), Computer model technical description and users guide, Utah Water Research Laboratory and USDA Forest Service Intermountain Research Station, http://www.engineering.usu.edu/dtarb/, last access: 17 August 2009, 1996.

Yen, Y.-C.: The rate of temperature propagation in moist porous mediums with particular reference to snow, J. Geophys. Res., 72, 1283-1288, 1967. 